\title{
THE STABILITY OF THE SANDWICH CONICAL SHELL PANEL - THE STRESS STATE ANALYSIS
}

\author{
Edward Tertel, Piotr Kuryto
}

Original scientific paper

The paper presents an analysis of the stress state in a sandwich open conical shell panel. The shells under consideration consist of two face-layers (facings, claddings) and a core layer. The facings are load-carrying, a core layer is lightweight and it resists transverse shear only. The facings are made of isotropic, compressible, work-hardening materials. The core is the greater part of the whole shell thickness (over $80 \%$ ). The shell under consideration is two-parametrical loaded. Pre-buckling deformation of the shell could occur within the elastic, elastic-plastic or plastic range. In order to determine the stress state which occurs during stability loss, the constitutive relations of the Nadai-Hencky deformation (NHd) theory, alongside the HMH (HuberMises-Hencky) yield condition, are accepted. The results obtained from the analysis show that during stability loss, the effective stress may temporarily decrease. Then the unloading and hardening phenomena could occur and this should be taken into consideration.

Keywords: buckling; deformation; sandwich shell; stability; stress

Stabilnost konusne panel oplate slojevite konstrukcije - analiza stanja naprezanja

Izvorni znanstveni članak

U radu se daje analiza stanja naprezanja konusne panel oplate slojevite konstrukcije. Analizirana oplata sastavljena je od dva vanjska sloja (obloge) $\mathrm{i}$ srednjeg sloja. Obloge podnose opterećenje, srednji sloj je male težine i odupire se samo poprečnom smiku. Obloge su od izotropnih, stlačivih materijala za otvrdnjivanje zbog obrade. Središnji sloj zauzima veći dio debljine čitave oplate (preko 80 \%). Razmatrana oplata je dvo-parametarski opterećena. Do deformacije pred-izvijanja oplate može doći u okviru elastičnog, elastično-plastičnog ili plastičnog područja. Kako bi se odredilo stanje naprezanja do kojeg dolazi tijekom gubitka stabilnosti, prihvaćeni su konstitutivni odnosi Nadai-Hencky teorije deformacije uz Huber-Mises-Hencky(HMH) uvjet popuštanja. Dobiveni rezultati pokazuju da tijekom gubitka stabilnosti može doći do privremenog smanjenja efektivnog naprezanja. Tada može doći do pojave rasterećenja i kaljenja i treba ju uzeti u obzir.

Ključne riječi: deformacija; izvijanje; naprezanje; panel oplata; stabilnost

\section{Introduction}

Thin-walled structures consisting of three layers have features that make them interesting for designers and builders of lightweight, modern constructions. The most important feature is a structural efficiency which is high. Layered, light-weight structures are more often used to design different constructions (e.g. fuselages, tanks, pipes, buildings elements). For this reason, these structures are well recognized and widely examined in the scientific study. An analysis of different thin-walled, layered structures (shells and plates) under the action of various loading is presented in $[1 \div 4]$. The main advantage of such structures is relatively high value of the load-to-weight ratio. The designed structures are characterized by advantageous compressive buckling strength as well as bending stiffness while they also have a relatively low weight. An interesting analysis of a structural behaviour of sandwich panels with construction cut-outs is presented in [5]. Certain types of engineering shell structures (e.g. train bodies, aircraft fuselages) are quite often in the shape of a cone. Therefore, in specified applications, an analysis of the three-layer, cone-shaped shell panel under certain type of external loads (longitudinal force and perpendicular pressure) may be interesting case studies. Strength and stability of cylindrical, conical and rectangular structures are considered by many authors. Scientific papers refer to different kinds of shell structures. The single-layer shells are considered in [6, 7], whereas the bi-layered in [9] and sandwich ones in $[9 \div 13]$. Works $[3,4]$ present different approaches and methods of sandwich structures analysis and the authors give large reference lists there. The empirical results of buckling analysis of thin-walled conical shells under external pressure are presented in [7]. An interesting new method of empirical measurement of strains and stress fields in loaded structures is presented in [14]. A majority of publications accept some initial assumptions concerning changes in stress values. Most publications assume the active loading process (Shanley approach)

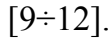

This article shows a way to determine stress changes during stability loss. This allows adopting an appropriate method of loading of a construction (constant load or active load approaches).A theoretical investigation of the stress changes in the three-layered conical shell under the action of complex loading is the main aim of presented study.

\subsection{The initial assumptions}

At the beginning of the considerations, some initial assumptions have to be adopted. The object under consideration is a three-layer conical shell segment. The shell consists of two thin face-layers and one core layer (Fig. 1a). In this consideration the face-layers are of equal thicknesses and are made of the same material which is compressible and isotropic. Other considerations, especially for unsymmetrical shells, could be seen in the previous publications $[10,11]$. The internal-core layer is made of a foam plastic that is assumed to be elastic, and incompressible in the radial ( $z$-axis) direction. For this layer the transverse shear is the only stress that it resists. The analysed shell is geometrically and physically symmetrical. The coordinate system adopted in the 
analysis is located on the symmetry surface and is shown in Fig. 1a.

Additionally, some general assumptions have been adopted in relation to the preceding shell structure. These assumptions are as follows:

- the general theory of thin-layered shells, and geometrical nonlinearity are compulsory,

- the Kirchhoff-Love theory is obligatory for the analysed shell and the displacement in the direction normal to the reference surface does not depend on the $z$-coordinate,

- the bilinear stress-strain relation describing the elastic-plastic characteristic of the facings is accepted and the NHd theory of plasticity together with the
$\mathrm{HMH}$ yield condition, are the essential relations used in the analysis,

- the prebuckling stress state is the membrane one, and the stress state after stability loss could be either elastic, elastic-plastic or plastic

- the shell is shallow, thin-walled and geometrically perfect.

\section{$2 \quad$ Loading and stresses}

The external loadings acting on the shell are schematically depicted on Fig. 1b. As could be seen there are two external loadings. The first one, acting on the curvilinear edges of the shell is the longitudinal force $N_{a}$, $N_{b}$. The second is the uniform surface pressure $q$ acting perpendicularly to the shell reference surface.
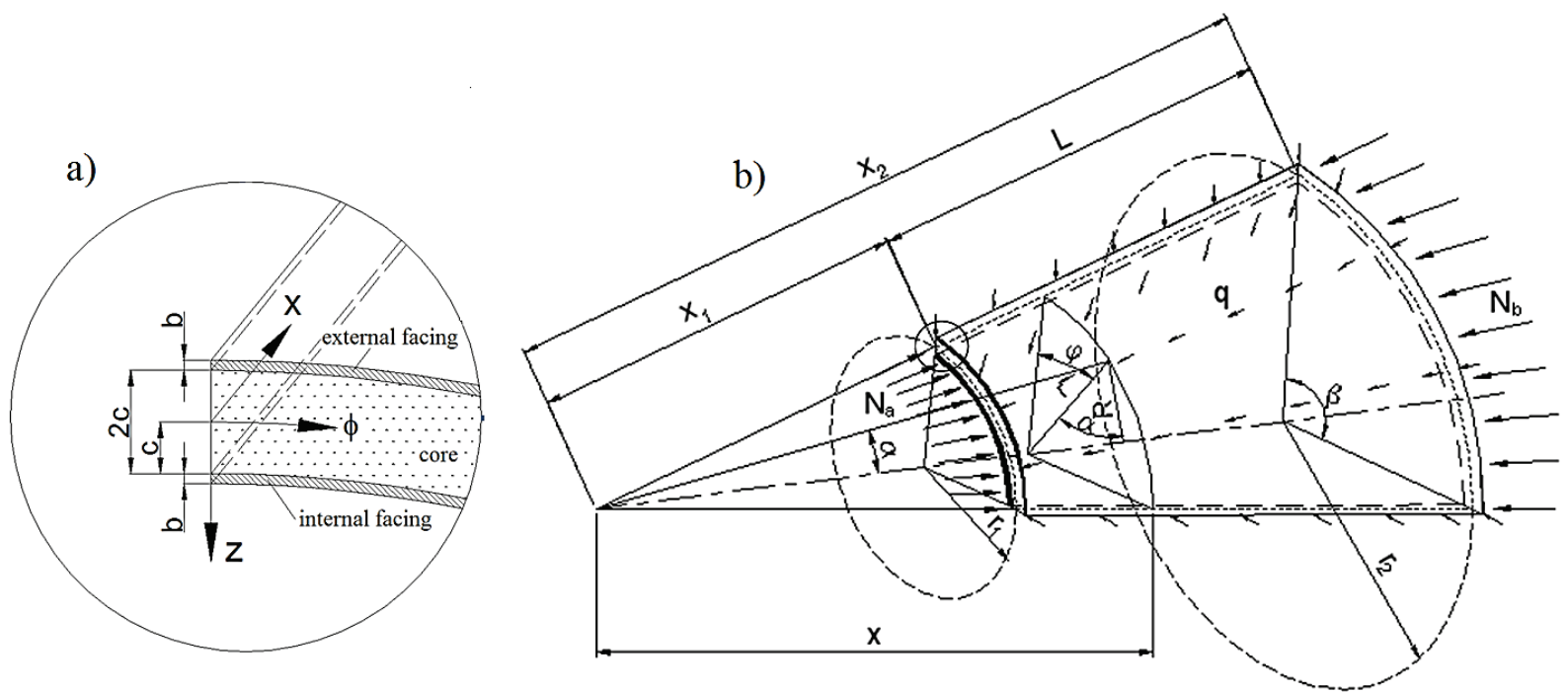

Figure 1 The model of the shell under consideration: a) the coordinate system and layers thickness, b) the geometry and external loadings

The internal forces in a membrane stress state vary on the $x$-coordinate and are described as follows:

- from the compressive axial forces:

$$
\begin{aligned}
& N_{x N}=\sigma_{x N} \cdot 2 b=-N_{a} \frac{x_{1}}{x}, \\
& N_{\phi N}=0, \\
& T_{x \phi N}=T_{\phi x N}=0,
\end{aligned}
$$

- from the lateral pressure:

$$
\begin{aligned}
& N_{x q}=\sigma_{x q} \cdot 2 b=\frac{1}{2} q \cdot x \cdot \tan \alpha \cdot\left[\left(\frac{x_{1}}{x}\right)^{2}-1\right], \\
& N_{\phi q}=\sigma_{\phi q} \cdot 2 b=-q \cdot x \cdot \tan \alpha \\
& T_{x \phi}=T_{\phi x}=0 .
\end{aligned}
$$

- $\quad$ from the total two-parametrical load:

$$
\begin{aligned}
& N_{x}=\sigma_{x} \cdot 2 b=\frac{1}{2} q \cdot x \cdot \tan \alpha \cdot\left[\left(\frac{x_{1}}{x}\right)^{2}-1\right]-N_{a} \frac{x_{1}}{x}, \\
& N_{\phi}=\sigma_{\phi} \cdot 2 b=-q \cdot x \cdot \tan \alpha \\
& T_{x \phi}=T_{\phi x}=0 .
\end{aligned}
$$

The limitation of the NHd theory which is used in this work is the condition of proportional loading. To meet this limitation, the constant value of the ratio of the external loadings must be established for each calculation. This was achieved by introducing the parameter described as follows:

$\kappa=\frac{N_{a}}{q \cdot x_{1}}=$ const.

The stress components and the effective stress in the pre-buckling state of stress can accordingly be expressed by the loadings acting on the shell:

$$
\begin{aligned}
\sigma_{x} & =\frac{-q \cdot x \cdot \tan \alpha}{4 b} \cdot k, \\
\sigma_{\phi} & =\frac{-q \cdot x \cdot \tan \alpha}{2 b}, \\
\tau_{x \varphi} & =0
\end{aligned}
$$

and the effective stress: 


$$
\begin{aligned}
& \sigma_{i}=\sqrt{\sigma_{x}{ }^{2}-\sigma_{x} \cdot \sigma_{\phi}+\sigma_{\phi}{ }^{2}+3 \tau_{x \phi}{ }^{2}}= \\
& =\frac{q \cdot x \cdot \tan \alpha}{4 b} \sqrt{k^{2}-2 k+4} \\
& \text { where, } k=\left(1-\left(\frac{x_{1}}{x}\right)^{2} \cdot\left(1-\kappa \frac{2}{\tan \alpha}\right)\right) .
\end{aligned}
$$

\section{Stability analysis}

The main objective in this work is calculation of the total effective stress that occurs during the stability loss. To obtain this aim, the values of the critical loads should be calculated firstly. The previous works of the authors relate to this problem $[10,11]$. Those articles present the procedures for calculations of the critical loads and obtaining the equilibrium paths. Therefore, in this work the calculation procedure will be described only in a general manner. The strain energy method is adopted in order to obtain the stability equations concerning the shell under consideration. In order to solve these equations, the Ritz method was applied.

The displacement constituents $u, v, w$ of the arbitrary point of the particular layer are related to the displacements of the points on the middle surfaces of the particular facing $u_{1}, u_{2}, v_{1}, v_{2}$ (Fig. 2) by the so called broken line approach.

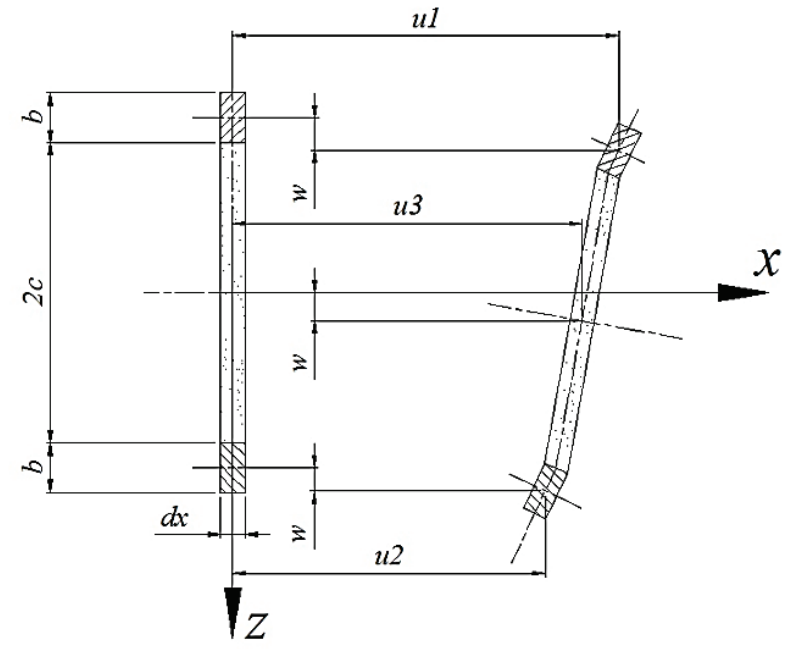

Figure 2 Scheme of the displacements of the sandwich shell element on the $x-z$ plane

The relations describing displacements components can be derived separately for each particular layer:

- the upper face-layer $[-c-b \leq z \leq-c]$ :

$$
\begin{aligned}
& u=u_{\alpha}+u_{\beta}-\left(z+c+\frac{b}{2}\right) \frac{\partial w}{\partial x}, \\
& v=v_{\alpha}+v_{\beta}-\left(z+c+\frac{b}{2}\right) \frac{1}{r} \frac{\partial w}{\partial \phi},
\end{aligned}
$$

- the core-layer $[-c \leq z \leq c]$ :

$$
\begin{aligned}
& u=u_{\alpha}-\frac{z}{c}\left[u_{\beta}-\frac{b}{2} \frac{\partial w}{\partial x}\right], \\
& v=v_{\alpha}-\frac{z}{c}\left[v_{\beta}-\frac{b}{2 r} \frac{\partial w}{\partial \phi}\right],
\end{aligned}
$$

- the lower face-layer $[c \leq z \leq c+b]$ :

$$
\begin{aligned}
& u=u_{\alpha}-u_{\beta}-\left(z-c-\frac{b}{2}\right) \frac{\partial w}{\partial x} \\
& v=v_{\alpha}-v_{\beta}-\left(z-c-\frac{b}{2}\right) \frac{1}{r} \frac{\partial w}{\partial \phi}
\end{aligned}
$$

where: $u_{\alpha}, u_{\beta}, v_{\alpha}, v_{\beta}$ are described by the particular facings displacements $[1,2]$ :

$$
\begin{array}{ll}
u_{\alpha}=\frac{u_{1}+u_{2}}{2}, & u_{\beta}=\frac{u_{1}-u_{2}}{2}, \\
v_{\alpha}=\frac{v_{1}+v_{2}}{2}, & v_{\beta}=\frac{v_{1}-v_{2}}{2} .
\end{array}
$$

The non-linear geometric relations quoted in [1] with the displacements derived in Eqs. (7) $\div(9)$ give the possibility to derive relations for the strains in the shell. The effective stress that occurs in the facings can be greater than the yield stresses specified for the facings material. In this case, the constitutive relations of the NHd theory of plasticity have to be applied in order to derive the stability equations.

Matrix form of the set of equations describing the internal forces developed as a result of buckling can be expressed for particular facing:

$$
\begin{aligned}
& {\left[\begin{array}{l}
\delta N_{x(j)} \\
\delta N_{\phi(j)} \\
\delta T_{(j)}
\end{array}\right]=\left[\begin{array}{ccc}
B_{11(j)} & B_{12(j)} & -B_{13(j)} \\
B_{21(j)} & B_{22(j)} & -B_{23(j)} \\
-B_{31(j)} & -B_{32(j)} & B_{33(j)}
\end{array}\right] \times\left[\begin{array}{l}
\delta \varepsilon_{x(j)} \\
\delta \varepsilon_{\phi(j)} \\
\delta \gamma_{x \phi(j)}
\end{array}\right]} \\
& {\left[\begin{array}{l}
\delta M_{x(j)} \\
\delta M_{\phi(j)} \\
\delta H_{(j)}
\end{array}\right]=\left[\begin{array}{ccc}
-D_{11(j)} & -D_{12(j)} & D_{13(j)} \\
-D_{21(j)} & -D_{22(j)} & D_{23(j)} \\
D_{31(j)} & D_{32(j)} & -D_{33(j)}
\end{array}\right] \times\left[\begin{array}{l}
\delta \kappa_{x(j)} \\
\delta \kappa_{\phi(j)} \\
\delta \kappa_{x \phi(j)}
\end{array}\right]}
\end{aligned}
$$

where: $j=1,2$ for the external and internal facing respectively.

The coefficients in Eqs. (11) are the local stiffness coefficients which correspond to the NHd theory of plasticity.

The set of the stability equations, expressed by the displacements does not have an explicit solution. The virtual work principle and the strain energy methods comprise a basis for obtaining equilibrium equations for the considered shell. As far as the sandwich shell, the total strain energy is the sum of the strain energy of the specified layers. Denoting the work of external loadings by $L_{z}$ the following relations can be formulated:

$$
\delta U_{p}=\delta\left(U_{w}^{(1)}+U_{w}^{(2)}+U_{w}^{(3)}+L_{z}\right)=0 .
$$


where: ${ }^{(1),(2)}$ - the facings, ${ }^{(3)}$ - the core layer.

The expressions in Eq. (12) were formulated in details in $[10,11]$.

The appropriate displacement functions have to be established. These functions must fulfil the boundary conditions that concern the free-supported shell. These conditions are: there are no deflections at the longitudinal edges as well as at the circumferential ones, the displacements along the all supported edges are equal to zero, the relative displacements of the facings at the edges are equal to zero. The displacement functions that satisfy the above boundary conditions are accepted $[1,10 \div 12]$ :

$$
\begin{aligned}
& u_{\alpha}(x, \phi)=A_{2} r^{2} \cos \left(k\left(x-x_{1}\right)\right) \sin (p \phi), \\
& u_{\beta}(x, \phi)=A_{3} r^{2} \cos \left(k\left(x-x_{1}\right)\right) \sin (p \phi), \\
& v_{\alpha}(x, \phi)=A_{4} r^{2} \sin \left(k\left(x-x_{1}\right)\right) \cos (p \phi), \\
& v_{\beta}(x, \phi)=A_{5} r^{2} \sin \left(k\left(x-x_{1}\right)\right) \cos (p \phi), \\
& w(x, \phi)=A_{1} r^{2} \sin \left(k\left(x-x_{1}\right)\right) \sin (p \phi) .
\end{aligned}
$$

where: $A_{i}$ are the free parameters to be determined in the solution procedure, $k, p$ are the parameters that depend on deformation modes.

Applying relations for the displacements (Eq. 13) in the non-linear geometrical equations, the complete form of equation (Eq. 12) describing potential energy of the shell is derived. Then the Ritz method is applied. In accordance with this method the partial derivatives of the entire potential energy with respect to the parameters $A_{i}$ have to be derived and compared to zero. A set of five equations is then obtained. The general matrix form of these equations is as follows:

$$
\left[\begin{array}{ccccc}
a_{11}+a_{11 p} & a_{12} & a_{13} & a_{14} & a_{15} \\
a_{21} & a_{22} & a_{24} & a_{24} & a_{25} \\
a_{31} & a_{32} & a_{33} & a_{34} & a_{35} \\
a_{41} & a_{42} & a_{43} & a_{44} & a_{45} \\
a_{51} & a_{52} & a_{53} & a_{54} & a_{55}
\end{array}\right] \times\left[\begin{array}{c}
A_{1} \\
A_{2} \\
A_{3} \\
A_{4} \\
A_{5}
\end{array}\right]=\left[\begin{array}{c}
b_{11} A_{1}^{2}+b_{12} A_{1}^{3}+b_{13} A_{1} A_{2}+b_{14} A_{1} A_{3}+b_{15} A_{1} A_{4}+b_{16} A_{1} A_{5}+b_{17} \\
b_{21} A_{1}^{2} \\
b_{31} A_{1}^{2} \\
b_{41} A_{1}^{2} \\
b_{51} A_{1}^{2}
\end{array}\right]
$$

where: $a_{i j}, \quad b_{i j}$ are the coefficients that depend on geometrical and physical characteristics of the shell as well as on buckling mode, and external actions.

The set of equations Eqs. (14) is solved with respect to the free parameter $A_{1}$ which is present in the equation describing displacement in the $z$-direction Eq. (13 5). Then, carrying out some transformations, a final form of solutions is obtained:

$$
q=\frac{e_{1} A_{1}+e_{2} A_{1}^{2}+e_{3} A_{1}^{3}}{A_{1} e_{4} \kappa+e_{5}} .
$$

where: $e_{i}$ are the coefficients of the stability equation which depends on the coefficients from Eq. (14) and thus also depends on the geometrical and physical characteristics of the shell as well as on buckling mode, and external actions.

It is impossible to gain an explicite solution to Eq. (15) because the coefficients $\left(e_{i}\right)$ in this equation depend on the external loadings and can vary when loadings are changing. A solution could be obtained numerically, using an iterative algorithm. Therefore, the appropriate algorithm has been applied and a special computer program code has been developed. The computer program enables to perform numerical calculations and elastic-plastic analysis of the shell under consideration. In Fig. 3 and Fig. 4 there are sample diagrams of the equilibrium paths made for different values of the parameter $\kappa$ and for the shell that is described by the parameters, given in Section 4. The curves in Fig. 3 show influence of the parameter $\kappa$ upon the critical load $q$. As it could be seen, increasing the parameter $\kappa$ results in a decreasing in the critical surface pressure.
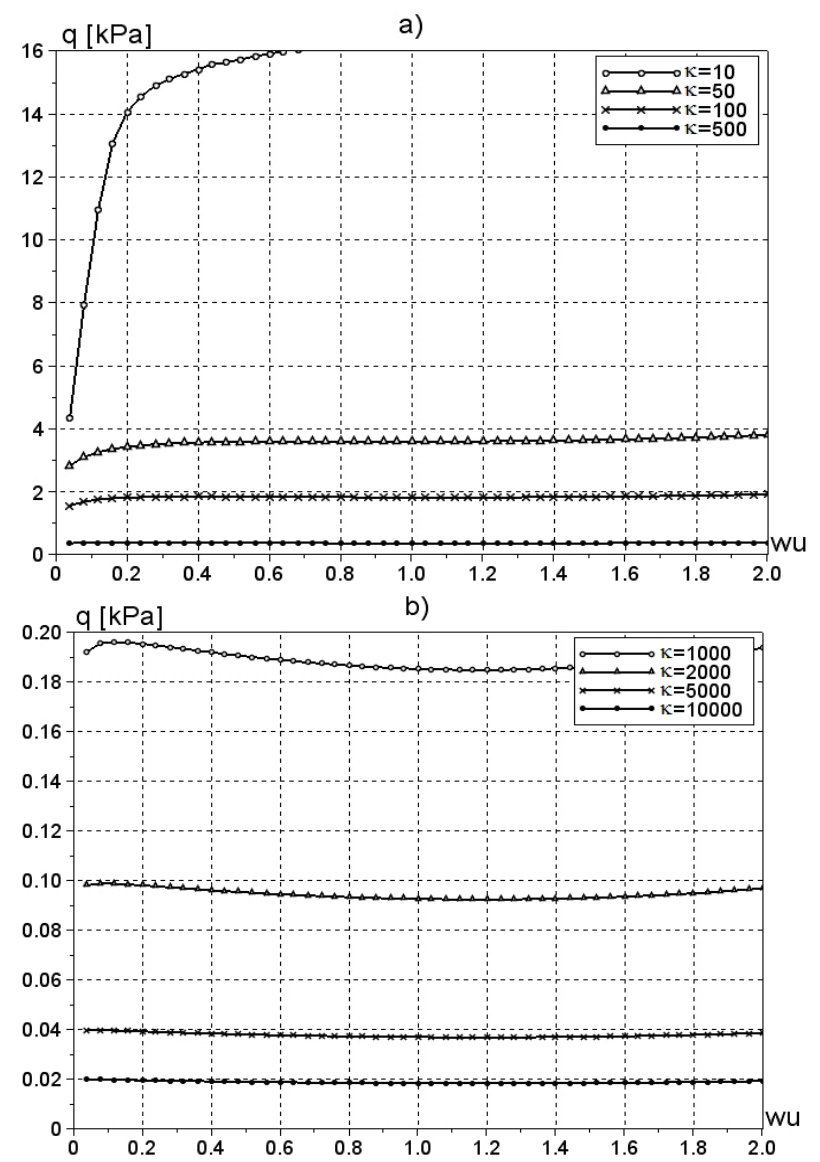

Figure 3 Equilibrium paths for surface pressure $q$ and various values of the parameter $\kappa$ : a) $\kappa=10 \div 500$, b) $\kappa=10^{3} \div 10^{4}$ 
Changes in the critical load $q$ are inversely proportional to changes in the parameter $\kappa$ in the whole range of deflection $w_{u}$. The curves in Fig. 4 show influence of the parameter $\kappa$ upon the critical load $N_{a}$. In that case, increasing of the parameter $\kappa$ results in increasing of the critical longitudinal force too. Furthermore, if the parameter $\kappa$ has value higher than 50, the upper and lower critical load can be determined. In that case, we can observe increasing of the deflection without increasing of the load or even with decreasing of the load.

We are dealing here with a typical case of stability loss, where the upper and lower critical loads can be determined. It can be concluded that, if the total external load has increased participation of the longitudinal force, the shell is more susceptible to buckling.
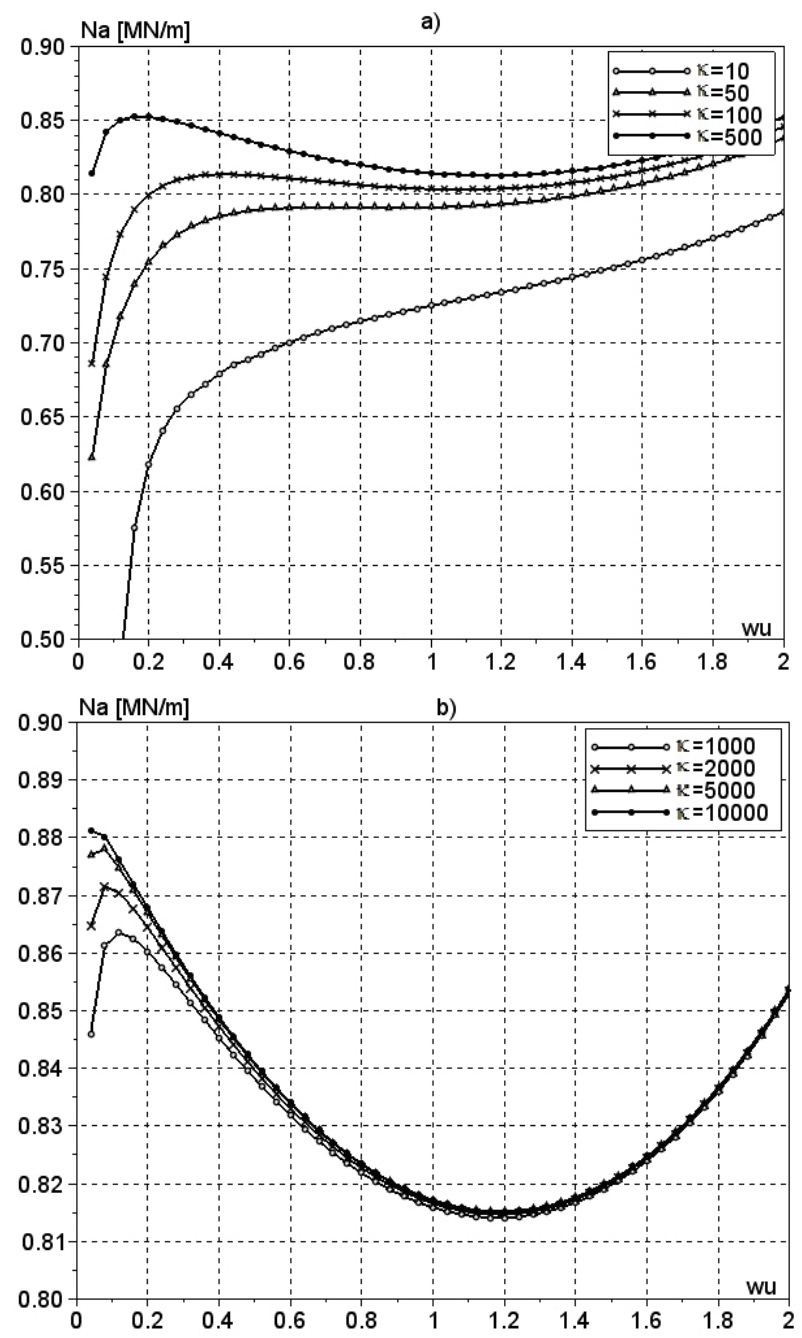

Figure 4 Equilibrium paths for longitudinal force $N_{a}$ and various values of the parameter $\kappa$ : a) $\kappa=10 \div 500$, b) $\kappa=10^{3} \div 10^{4}$

\section{The stress state analysis}

The objective of this work is to determine the stress state in the face layers of the shell under consideration (Fig. 1) during stability loss. Based on the values of the critical load, that has been previously calculated, we can compute the stresses occurring in the facings. The computations were performed with respect to the increasing values of the parameter $w_{u}$ defined as follows: $w_{u}=\frac{w}{2(b+c)}=$ const.

The second parameter which is taken into account is the parameter $\kappa$, which represents the ratio between the loadings (Eq. (4)). The variability of the stress along the $x$-coordinate is investigated too.

In the performed calculations, the following input data were accepted.

Table 1 Material properties

\begin{tabular}{|c|c|c|c|c|c|}
\hline & $\begin{array}{c}\mathrm{E} \\
\mathrm{MPa}\end{array}$ & $\begin{array}{c}E_{\mathrm{t}} \\
/ \mathrm{MPa}\end{array}$ & $v$ & $\begin{array}{c}\sigma_{\mathrm{p}} \\
/ \mathrm{MPa}\end{array}$ & $\begin{array}{c}G_{3} \\
/ \mathrm{MPa}\end{array}$ \\
\hline Facings & 210000 & 30000 & 0,3 & 320 & - \\
\hline Core & - & - & - & - & 16 \\
\hline
\end{tabular}

Table 2 Geometrical parameters (see fig. 1)

\begin{tabular}{|c|c|c|c|c|c|}
\hline$L / \mathrm{m}$ & $r_{1} / \mathrm{m}$ & $2 c / \mathrm{mm}$ & $b / \mathrm{mm}$ & $\alpha /^{\circ}$ & $\beta /^{\mathrm{o}}$ \\
\hline 1,4 & 2,2 & 16 & 0,8 & 30 & 30 \\
\hline
\end{tabular}

Additionally, some overall parameters were accepted for the analysis. These parameters are:

- Loadings ratio: $\kappa=10 \div 10^{4}$

- $\quad$ Buckling mode defined by numbers of half-waves ( $m$ $=1, n=1)$ along the $x, \varphi$ coordinates respectively,

- Maximum of the shell deflection parameter $\max \left(w_{u}\right)=2$.

The effective stress (sig) being a function of deflection $\left(w_{u}\right)$ and $x$-coordinate $(L x)$ is the basis for presentation and analysis of the results $\left\{\operatorname{sig}\left(w_{w}, L x\right)\right\}$. Individual surfaces in Fig. 5 are graphed for particular value of the parameter $\kappa$ and depict the changes in the stress depending on the $x$-coordinate and for various values of the shell deflections.

As may be noted, the shape of the surfaces in Fig. 5 and curves in Fig. 7 resembles the shape of the equilibrium paths shown in Fig. 4.

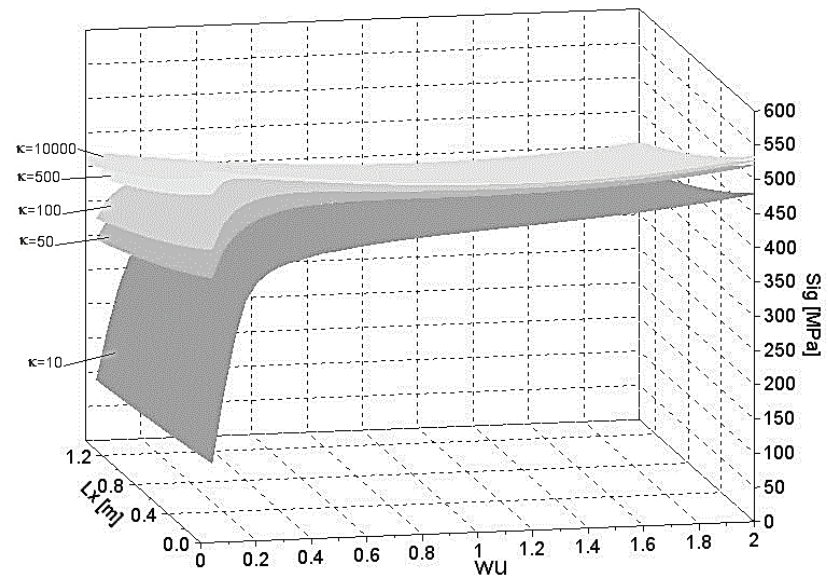

Figure 5 The effective stress (Sig) versus the deflection $\left(w_{u}\right)$ and the $x$ coordinate $(L x)$ for different value of the parameter $\kappa$; $\left(L x=x-x_{1}\right.$ - see Fig. 1)

The effective stress initially increases intensively. When the deflection parameter reaches a certain value, the effective stress reaches the extreme point (maximum) and the process of stability loss is initiated (for $\kappa=50$ or more). Then a drop in the effective stress can be observed. After that, having reached the next extremum (minimum), the effective stress increases again. When the parameter $\kappa$ reaches higher values, the first extreme point (maximum) 
corresponds to the lower value of the deflection. The second extreme point (minimum) corresponds to the same value of the deflection, regardless of the parameter $\kappa$ (see Fig.7).

It is noteworthy that the position of the extreme points is not dependent on the $x$-coordinate. On the other hand, the effective stress value depends on the $x$ coordinate, which can be clearly seen in Fig. 6 . If the $x$ coordinate increases (towards a bigger shell radius) the effective stress drops down linearly. The relative decrease of the effective stress does not depend on the value of the parameter $\kappa$ and for the considered shell, reaches the value of $24,1 \%$.

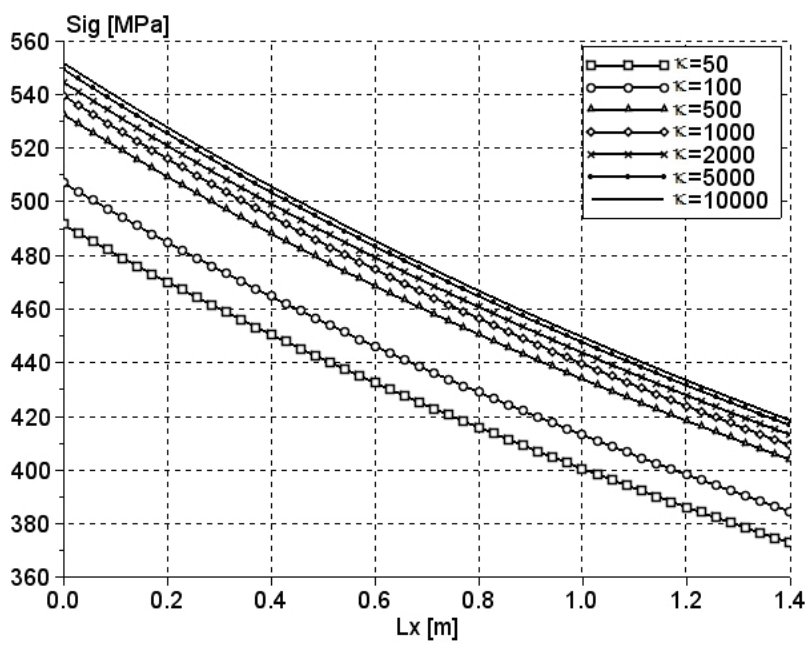

Figure 6 The effective stress corresponds to the upper critical load versus the $x$-coordinate $(L x) ;\left(L x=x-x_{1}-\right.$ see Fig. 1$)$

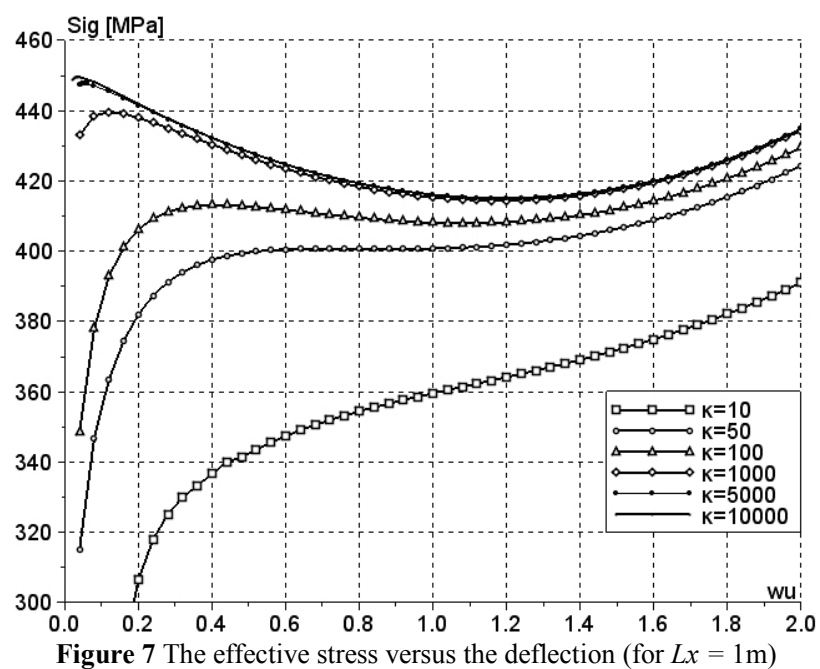

\section{Conclusions}

The objective of this paper is to analyse the state of stress in the three-layer conical shell during stability loss. For the shell with the parameters accepted in the analysis, the stability loss process occurs in the elastic-plastic or plastic state of stress. The changes in the effective stress during stability loss on the entire length of the shell are presented and analysed. The results, as presented, show that during stability loss, the effective stress may decrease over the whole length of the shell (the unloading process). If this occurs, it seems to be more appropriate to use the so-called constant load concept (the Engesser-Karman approach) which takes into consideration the unloading and hardening of the material after stability loss. The constant load approach is a better approach from the theoretical point of view because it takes into consideration the unloading of the material. This approach will be considered in subsequent studies.

\section{References}

[1] Zielnica, J. Stability of elastic-plastic shells (in Polish). Poznan Uni. of Tech., 2001

[2] Magnucki, K.; Ostwald, M. Stability and optimization of sandwich structures (in Polish).- Red. of collective work, Poznan Uni. of Tech - Uni. of Zielona Gora, 2001.

[3] Hohe, J.; Librescu, L. Advances in the structural modeling of elastic sandwich panels. // Mechanics of Advanced Materials and Structures. 11, 4-5(2004), pp. 395-424. DOI: 10.1080/15376490490451561

[4] Vinson, J. R. Sandwich Structures. // Applied Mechanics Reviews. 54, 3(2001), pp. 201-214. DOI: 10.1115/1.3097295

[5] Čuk, M.; Štih, S.; Jerman, B. Finite element analysis of sandwich panels with longitudinal joints and large openings. // Tehnicki vjesnik-Technical Gazette.20, 2(2013), pp. 275-284.

[6] Błachut, J. On elastic-plastic buckling of cones. // Thin Walled Structures. 49(2011), pp. 45-52. DOI: 10.1016/j.tws.2010.08.005

[7] Golzan, B. S.; Showkati, H. Buckling of thin-walled conical shells under uniform external pressure. // Thin-Walled Structures. 46(2008), pp. 516-529. DOI: 10.1016/j.tws.2007.10.011

[8] Paczos, P.; Zielnica, J. Stability of orthotropic elasticplastic open conical shells. // Thin-Walled Structures. 46, 5(2008), pp. 530-540. DOI: 10.1016/j.tws.2007.10.006

[9] Jaskula, L.; Zielnica, J. Large displacement stability analysis of elastic-plastic unsymmetrical sandwich cylindrical shells. // Thin Walled Structures. 49, 5(2011), pp.611-617. DOI: 10.1016/j.tws.2010.09.004

[10] Tertel, E. Stability of elastic-plastic sandwich conical shells with a change in the thickness of face-layers. // Journal of Vibroengineering. 15, 2(2013) pp. 684-692.

[11] Tertel, E.; Cyganiuk, J.; Kuryło, P.Buckling of elasticplastic sandwich conical shells - theoretical studies. // International Journal of Applied Mechanics and Engineering. 16, 1(2011), pp.129-140.

[12] Zielnica, J. Non-linear stability of elastic-plastic conical shell under combined load. // Journal of Theoretical and Applied Mechanics, 41, 3(2003), pp. 693-709.

[13] Tertel, E.; Kuryło, P.; Papacz, W. Parallelepiped sandwich shell - searching for the optimal geometric parameters. // Applied Mechanics and Materials.611, (2014), pp. 170-174. DOI: 10.4028/www.scientific.net/AMM.611.170

[14] Trebuna, F.; Frankovsky, P.; Bocko, J.; Pastor, M. New posibilities of using PhotoStress method. // Acta Mechanica Slovaca. 15, 4(2011), pp. 44-51.

\section{Authors' addresses}

Edward Tertel, Dr Eng.

University of Zielona Góra, Faculty of Mechanical Engineering ul. Prof. Z. Szafrana 4, 65-516 Zielona Góra, Poland E-mail: E.Tertel@ibem.uz.zgora.pl

Piotr Kuryto, DrHab. Eng., Prof. Dr.

University of Zielona Góra, Faculty of Mechanical Engineering ul. Prof. Z. Szafrana 4, 65-516 Zielona Góra, Poland E-mail: P.Kurylo@ibem.uz.zgora.pl 